\title{
Comparison of serum, salivary, and rapid whole blood diagnostic tests for Helicobacter pylori and their validation against endoscopy based tests
}

\author{
T G Reilly, V Poxon, D S A Sanders, T S J Elliott, R P Walt
}

\begin{abstract}
Background-A rapid, reliable, and accurate test for the diagnosis of infection with Helicobacter pylori is needed for screening dyspeptic patients before referral for endoscopy.

Aim-To compare a new rapid whole blood test (Helisal rapid blood, Cortecs), two serum enzyme linked immunosorbent assays (ELISAs; Helico-G, Shield and Helisal serum, Cortecs), and a salivary assay (Helisal saliva, Cortecs), with slide biopsy urease, ${ }^{13} \mathrm{C}$-urea breath test, and histology.

Methods-Three hundred and three consecutive dyspeptic patients attending for gastroscopy underwent two antral biopsies for histology, and one for rapid slide biopsy urease test for assessment of $H$ pylori status. Blood and saliva were also collected. One hundred of the patients also underwent a ${ }^{13} \mathrm{C}$-urea breath test. Gold standard positives were defined as those with at least two positive tests among slide urease, breath test, or histology, and gold standard negatives as those with all these (or two when the breath test was not done) negative.
\end{abstract}

Results-Of 300 patients (median age 63, range 28-89) eligible for analysis, 137 $(46 \%)$ were gold standard positives, of which Helisal rapid blood identified 116, Helico-G 129, Helisal serum 130, and Helisal saliva 120; 137 (46\%) were gold standard negatives of which the number falsely identified as positive was 30 by Helisal rapid blood, 45 by Helico-G, 41 by Helisal serum, and 41 by Helisal saliva. Sensitivities and specificities were: for the whole blood test $85 \%$ and $78 \%$ respectively; for Helico-G $94 \%$ and $67 \%$, for Helisal serum $95 \%$ and $70 \%$, and for Helisal saliva $84 \%$ and $70 \%$.

Conclusions-If endoscopy had been undertaken only on patients with positive tests two of 16 duodenal ulcers would have been missed if the Helisal rapid blood test was used, and one if any of the ELISA tests were used. None of the blood tests would have missed any of six gastric ulcers, but the salivary test would have missed one. (Gut 1997; 40: 454-458)

Keywords: Helicobacter pylori diagnosis, ELISA serology, rapid whole blood test, ${ }^{13} \mathrm{C}$-urea breath test, histology.
There are many methods available for the diagnosis of Helicobacter pylori. Some require upper gastrointestinal endoscopy to gain material for diagnosis, whereas non-invasive tests can be performed on serum, saliva, or expired breath samples. It has been suggested that screening for the presence of the organism before referral for upper gastrointestinal endoscopy $^{1}$ would allow resources to be directed towards those in whom pathology that is serious is likely to be encountered. It has been shown that $H$ pylori status as determined by serology predicts endoscopic findings more accurately than formal questioning. ${ }^{2}$ If this strategy were to be widely adopted an inexpensive, reliable, and rapid diagnostic test that is acceptable to patients and clinicians would be needed.

Aims

The study was designed primarily to compare the performance of several candidate screening tests, including a new rapid whole blood test (Helisal rapid blood, Cortecs Diagnostics, Clwyd) which is a near patient test giving a result within 10 minutes, with other established tests for the diagnosis of $H$ pylori. Subsidiary aims were to show whether correlations exist between the titre of different quantifiable assays for $H$ pylori antibodies and the endoscopic findings, and between the titre and the density of $H$ pylori infestation of the gastric mucosa.

\section{Methods}

Three hundred and three consecutive patients attending the endoscopy department of the Queen Elizabeth Hospital for "direct access" upper gastrointestinal endoscopy were recruited to take part in the study, which had the approval of the South Birmingham research ethics committee. The department operates a screening policy whereby open access endoscopy is not provided to those below the age of 50 with uncomplicated dyspepsia (no worrying symptoms), unless they have positive $H$ pylori serology.

The endoscopic findings were recorded by any of seven experienced endoscopists (four consultants and three research registrars) and three antral mucosal biopsy specimens were taken from each patient. Two biopsy specimens were sent for histological examination for pathology and the presence of $H$ pylori after 
staining with haematoxylin and eosin, and if no Helicobacter organisms were seen a modified Giemsa stain was applied. The presence or absence of $H$ pylori was noted and the severity of infection graded semiquantitatively from 1 to 3, the grades denoting small, moderate, and large numbers of Helicobacter seen. The remaining antral biopsy specimen was used for a slide biopsy urease test (CLOtest $^{\circledR}$, DeltaWest Pty, Australia). This was read at 30 minutes after insertion of the biopsy, reviewed at 24 hours, and the result recorded.

After endoscopy, $7 \mathrm{ml}$ venous blood was taken from each subject: this was centrifuged and the serum stored for enzyme linked immunosorbent assay (ELISA) for anti-Helicobacter IgG antibodies. Two test kits were used (Helico-G, Shield Diagnostics, Techno Park, Dundee, and Helisal serum, Cortecs) with antibody titres obtained by absorbance measurement at $450 \mathrm{~nm}$ after coincubation of immobilised antigen with test serum, horseradish peroxidase, and tetramethyl benzidine indicator. Not sooner than 30 minutes after endoscopy saliva was collected by an absorbent pad placed in the mouth until an indicator showed blue (Omnisal ${ }^{\mathrm{TM}}$ collection system). The saliva was assayed for $H$ pylori antibodies using the Helisal enzyme immunoassay.

A drop of blood was taken by lancet puncture of a fingertip into a capillary tube and this was tested by a rapid whole blood diagnostic kit (Helisal rapid blood, Cortecs), as previously described. A positive test was recorded if any dye was observed in the test area, and a negative if only the control spot showed red. When two independent blinded observers were in agreement that the mark was

TABLE I Performance of the tests under investigation and of the gold standard tests

\begin{tabular}{lclr}
\hline & $\begin{array}{l}\text { Sensitivity (\%) } \\
(95 \% \text { CI) }\end{array}$ & $\begin{array}{l}\text { Sensitivity (\%) if } \\
\text { indeterminates } \\
\text { positive (95\% CI) }\end{array}$ & $\begin{array}{l}\text { Specificity } \\
(95 \% \text { CI) }\end{array}$ \\
\hline $\begin{array}{l}\text { Helisal whole blood test } \\
\text { Helisal whole blood test } \\
\quad \text { (excluding faint results) }\end{array}$ & $85(71-91)$ & $78(71-84)$ & $78 \cdot 1(71-85)$ \\
Helico-G & $82 \cdot 5(76-89)$ & $75(68-82)$ & $84 \cdot 9(79-91)$ \\
Helisal serum & $94(89-97)$ & $87(82-92)$ & $67(59-75)$ \\
Helisal saliva & $95(90-98)$ & $90(85-94)$ & $70(62-78)$ \\
Histology & $84(76-89)$ & $79(73-85)$ & $70(62-77)$ \\
Slide biopsy urease test & $97(92-99)$ & $90(85-95)$ & $100(97-100)$ \\
${ }_{13}$ C-urea breath test & $91(85-95)$ & $91(85-95)$ & $100(97-100)$ \\
\hline
\end{tabular}

The middle column shows the sensitivities which would be found if all those who had indeterminate results by the gold standard definition were deemed positive.

TABLE II Sydney system grading of histology according to gold standard status in 295 patients

\begin{tabular}{|c|c|c|c|c|c|c|c|}
\hline \multirow{2}{*}{$\begin{array}{l}\text { Sydney } \\
\text { category }\end{array}$} & \multirow{2}{*}{$\begin{array}{l}\text { Gold } \\
\text { standard } \\
\text { status }\end{array}$} & \multicolumn{4}{|c|}{ Sydney grade } & \multirow{2}{*}{$\begin{array}{l}\text { \% Possible } \\
\text { score }\end{array}$} & \multirow{2}{*}{$\begin{array}{l}\text { \% With } \\
\text { any grade }\end{array}$} \\
\hline & & 0 & 1 & 2 & 3 & & \\
\hline$H$ pylori density & $\begin{array}{l}\mathbf{N} \\
\mathrm{I} \\
\mathrm{P}\end{array}$ & $\begin{array}{r}137 \\
11 \\
6\end{array}$ & $\begin{array}{r}0 \\
15 \\
50\end{array}$ & $\begin{array}{r}0 \\
0 \\
49\end{array}$ & $\begin{array}{r}0 \\
0 \\
27\end{array}$ & $\begin{array}{r}0.0 \\
19 \cdot 2 \\
57 \cdot 8\end{array}$ & $\begin{array}{r}0 \\
58 \\
95\end{array}$ \\
\hline Active gastritis & $\begin{array}{l}\mathrm{N} \\
\mathrm{I} \\
\mathrm{P}\end{array}$ & $\begin{array}{r}128 \\
22 \\
47\end{array}$ & $\begin{array}{r}9 \\
3 \\
44\end{array}$ & $\begin{array}{r}0 \\
1 \\
26\end{array}$ & $\begin{array}{r}0 \\
0 \\
15\end{array}$ & $\begin{array}{r}2 \cdot 2 \\
6 \cdot 4 \\
35 \cdot 6\end{array}$ & $\begin{array}{r}7 \\
15 \\
64\end{array}$ \\
\hline Chronic gastritis & $\begin{array}{l}\mathrm{N} \\
\mathrm{I} \\
\mathrm{P}\end{array}$ & $\begin{array}{r}84 \\
10 \\
8\end{array}$ & $\begin{array}{l}50 \\
12 \\
53\end{array}$ & $\begin{array}{r}3 \\
4 \\
47\end{array}$ & $\begin{array}{r}0 \\
0 \\
24\end{array}$ & $\begin{array}{l}13 \cdot 6 \\
25 \cdot 6 \\
55 \cdot 3\end{array}$ & $\begin{array}{l}39 \\
62 \\
94\end{array}$ \\
\hline Intestinal metaplasia & $\begin{array}{l}\mathrm{N} \\
\mathrm{I} \\
\mathrm{P}\end{array}$ & $\begin{array}{r}128 \\
22 \\
116\end{array}$ & $\begin{array}{r}8 \\
4 \\
13\end{array}$ & $\begin{array}{l}0 \\
0 \\
2\end{array}$ & $\begin{array}{l}1 \\
0 \\
1\end{array}$ & $\begin{array}{l}2 \cdot 7 \\
5 \cdot 1 \\
5 \cdot 1\end{array}$ & $\begin{array}{l}7 \\
15 \\
12\end{array}$ \\
\hline
\end{tabular}

$N=$ negative $(n=137) ; I=$ indeterminate $(n=26) ; P=$ positive $(n=132)$. hard to discern the positives were also noted to be "faint". One hundred of the patients also underwent a ${ }^{13} \mathrm{C}$-urea breath test (BSIA Ltd, Brook Lane North, Brentford, Middlesex) using the European Standard Protocol one sample method, ${ }^{3}$ and excess delta ${ }^{13} \mathrm{CO}_{2}$ excretion greater than 5 per mil was taken as a positive result.

Gold standard positives were defined as those with at least two positive tests among the rapid slide biopsy urease test, histology, and ${ }^{13} \mathrm{C}$-urea breath test; and gold standard negatives as those with all these tests negative (three tests or two when the ${ }^{13} \mathrm{C}$-urea breath test was not done). Those with conflicting results (one positive and either one or two negative) were classed as indeterminate.

\section{Results}

Three hundred and three subjects were enrolled and 300 were eligible for analysis (median age 62, range 28-89). Three subjects were excluded because data were missing (antral biopsy specimens were not taken in two cases and the blood sample for serology was missing in one case). There were 137 gold standard positives, of which the whole blood test identified 116, Helico-G 129, Helisal serum 130, and Helisal saliva 120. Of 137 gold standard negatives the whole blood test falsely identified 30 as positive, Helico-G 45, Helisal serum 41 , and the salivary assay 53 . In 26 cases results were indeterminate ( 17 of them had not had ${ }^{13} \mathrm{C}$-urea breath tests). Fifteen patients had positive histology only and 11 had a positive slide biopsy urease test only. Excluding the indeterminates the prevalence of $H$ pylori infection was $50 \%$. Table I shows the sensitivities and specificities derived both by excluding the indeterminates and by reading them as positive.

Faint marks were recorded with the rapid test in 29 cases. These did not correlate with borderline titres in the ELISA assays. Using the cut off of $11 \mathrm{U} / \mathrm{ml}$ for the Helico-G test, nine of 113 in the seronegative group were faint compared with 20 of 187 in the seropositive group $\left(p=0.44, \chi^{2}\right)$. Those with faint marks made up 11 of 137 of the gold standard positives and 16 of 137 of the gold standard negatives $\left(p=0.31, x^{2}\right)$. There were two patients with faint marks whose gold standard tests were indeterminate. Table 1 shows results assuming all faint marks to be positive in accordance with the manufacturers' instructions, and also excluding all faint marks.

\section{HISTOLOGY}

Histology results were available in 295 cases, and were lost or unsatisfactory in five. There were 154 cases with no organisms seen on microscopy, and 141 in which $H$ pylori was seen, including 65 with small, 49 with moderate, and 27 with large numbers of organisms. Table II shows the histological grading according to the Sydney system ${ }^{4}$ for each of the gold standard categories. Table III shows the grade of infection accorded to each diagnosis and 
comparisons of each diagnostic group with the normal subjects. There was a significant difference between those with peptic ulcer disease and normal subjects in the proportion with $H$ pylori infection $(p=0.0001)$. All other comparisons were not significantly different. The grade of infection was also compared with the antibody titre of the three ELISA assays studied (Table IV). All three assays showed a significant difference in mean titre between those with no histological evidence of $H$ pylori infection and those with organisms visible on the biopsy sample, but there was no difference between grades of infection.

\section{DIAGNOSES AND HELICOBACTER PYLORI} INFECTION

For the purposes of this analysis groupings were made of the diagnoses (Table V). Sixteen patients with duodenal ulcer and six with

TABLE III Histological grade of $\mathrm{H}$ pylori infection correlated with endoscopic diagnosis

\begin{tabular}{lrrrrrrl}
\hline & \multicolumn{1}{c}{} & \multicolumn{1}{c}{1} & \multicolumn{1}{c}{2} & 3 & $\begin{array}{l}\text { Any } \\
\text { grade }\end{array}$ & Total & $\begin{array}{l}\chi^{2} \text { v normal } \\
(p \text { value) }\end{array}$ \\
\hline Normal & 72 & 31 & 18 & 8 & 57 & 129 & - \\
Antral gastritis & 11 & 4 & 3 & 5 & 12 & 23 & 0.48 \\
Peptic ulcer disease & 6 & 12 & 11 & 5 & 28 & 34 & 0.0001 \\
Duodenitis & 6 & 3 & 3 & 3 & 9 & 15 & 0.25 \\
Oesophagitis & 32 & 7 & 10 & 3 & 20 & 52 & 0.48 \\
Hiatus herniat & 21 & 7 & 4 & 3 & 14 & 35 & 0.66 \\
\hline
\end{tabular}

*Numbers refer to patients in whom gastritis was the principal diagnosis only: gastritis was an additional diagnosis in 14 cases with other pathology.

tNumbers refer to patients in whom hiatus hernia was the sole diagnosis: it was also noted in a further 26 cases with oesophagitis.

fOesophagitis was an additional diagnosis in one patient with a duodenal ulcer and three patients with duodenitis.

TABLE IV Mean antibody titres ( $₫ 95 \%$ CIs) compared with histological grade of $\mathrm{H}$ pylori infection for each of three assays

\begin{tabular}{|c|c|c|c|c|}
\hline & \multicolumn{4}{|c|}{ Grade of $\mathrm{H}$ pylori infection } \\
\hline & $0(n=154)$ & $1(n=65)$ & $2(n=49)$ & $3(n=27)$ \\
\hline Helico-G & $25 \cdot 5( \pm 6 \cdot 85)$ & $\begin{array}{l}51 \cdot 3( \pm 10 \cdot 85) \\
p<0 \cdot 0001\end{array}$ & $\begin{array}{l}61 \cdot 9( \pm 12 \cdot 8) \\
\mathrm{p}<0.0001\end{array}$ & $\begin{array}{l}55 \cdot 1( \pm 19 \cdot 8) \\
p=0 \cdot 0092\end{array}$ \\
\hline Helisal serum & $1.73( \pm 0.4)$ & $\begin{array}{l}4.26( \pm 0 \cdot 77) \\
p<0.0001\end{array}$ & $p<0.0001$ & $p=0.0002$ \\
\hline Helisal saliva & $1.44( \pm 0.35)$ & $\begin{array}{c}3 \cdot 27( \pm 0 \cdot 75) \\
\mathrm{p}=0.0002\end{array}$ & $\begin{array}{l}3.83( \pm 0.87) \\
\mathrm{p}<0.0001\end{array}$ & $\begin{array}{c}4 \cdot 30( \pm 1 \cdot 20) \\
\mathrm{p}=0 \cdot 0007\end{array}$ \\
\hline
\end{tabular}

Statistical comparisons are with the histology zero group and are by oneway analysis of variance (ANOVA).

TABLE V Number (\%) of each diagnosis predicted by a positive serology result

\begin{tabular}{|c|c|c|c|c|}
\hline Diagnosis & Helisal rapid & Helico-G & Helisal serum & Helisal saliva \\
\hline $\begin{array}{l}\text { Oesophageal cancer }(n=5) \\
\text { Peptic ulcer }(n=22) \\
\text { Duodenal ulcer (previous) }(n=12) \\
\text { Duodenitis }(n=16) \\
\text { Hiatus hernia }(n=35) \\
\text { Normal }(n=132) \\
\text { Oesophagitis }(n=52) \\
\text { Antral gastritis }(n=24)\end{array}$ & $\begin{array}{r}2(40) \\
20(91) \\
7(58) \\
11(69) \\
17(49) \\
64(48) \\
23(44) \\
13(54)\end{array}$ & $\begin{array}{l}3(60) \\
21(95) \\
7(58) \\
12(75) \\
19(54) \\
80(60) \\
30(58) \\
15(62 \cdot 5)\end{array}$ & $\begin{array}{l}2(40) \\
21(95) \\
8(66) \\
12(75) \\
20(57) \\
84(64) \\
24(46) \\
16(66)\end{array}$ & $\begin{array}{l}0 \\
19(86) \\
6(50) \\
9(56) \\
18(51) \\
76(58) \\
23(44) \\
16(66)\end{array}$ \\
\hline
\end{tabular}

gastric ulcer were grouped as "peptic ulcer disease". Seven patients with a previously documented duodenal ulcer, two with previous surgery for ulcer (one partial gastrectomy and one vagotomy and pyloroplasty), and three with typical scarring and deformity of the duodenum without active ulcer at endoscopy, were grouped as "previous duodenal ulcer". A group of 243 patients labelled "oesophagitis or normal" comprised 57 with oesophagitis (including five with Barrett's oesophagus), 129 normal, 35 with hiatus hernia alone, and 23 with macroscopic antral gastritis. Fifteen patients had macroscopic duodenitis alone. There were five patients with cancer of the oesophagus.

There were two Helicobacter negative patients in the peptic ulcer disease group: one patient with duodenal ulcer was on a non-steroidal anti-inflammatory drug and the other had had previous Helicobacter eradication treatment. There were three in the "previous duodenal ulcer" group: two with previous ulcer surgery and one who had had a duodenal ulcer documented 15 years previously.

The mean antibody titres of the ELISA assays for each of the four main diagnostic groups were compared (Table VI). There was a significant difference between the peptic ulcer disease group and the oesophagitis or normal group for the two serum assays but not the salivary assay. In addition there was a significant difference between the peptic ulcer disease group and the duodenitis and previous duodenal ulcer groups for the Helisal serum assay.

\section{SUBGROUP ANALYSES}

\section{Relevant drugs excluded}

Because no exclusion criteria were imposed there were patients in the study who had had previous eradication therapy, or were currently taking proton pump inhibitors and nonsteroidal anti-inflammatory drugs. An analysis was undertaken of the performance of the tests with this group excluded. The number of indeterminates diminished from 26 to 21 . Table VII gives the results of this analysis, which showed virtually identical sensitivities to those of the entire group and improved specificities. The sensitivity of the slide biopsy urease test improved from $91 \%$ to $100 \%$.

Patients under the age of 50 years

The study included 47 patients under the age of 50 years and these were examined as a separate group (Table VIII). Of these, 36 were $H$ pylori positive (a high proportion, reflecting

TABLE VI Mean (SD) antibody titre grouped by endoscopic diagnosis

\begin{tabular}{lllllll}
\hline & Helico $G$ & & Helisal serum & \multicolumn{3}{c}{ Helisal saliva } \\
\hline Oesophagitis or normal $(\mathrm{n}=243)$ & $39 \cdot 8(50 \cdot 3)$ & - & $2.96(3.15)$ & - & $2 \cdot 46(2.92)$ & - \\
Peptic ulcer disease $(\mathrm{n}=22)$ & $60.9(37.4)$ & $\mathrm{p}=0.02$ & $6.02(2.56)$ & $\mathrm{p}=<0.001$ & $3.64(3.00)$ & $\mathrm{p}=0.09$ \\
Previous DU $(\mathrm{n}=12)$ & $35.4(43.9)$ & $\mathrm{p}=0.74$ & $3.01(2.79)$ & $\mathrm{p}=0.95$ & $2 \cdot 41(2.57)$ & $\mathrm{p}=0.95$ \\
Duodenitis $(\mathrm{n}=15)$ & $47.2(49.8)$ & $\mathrm{p}=0.57$ & $3.79(3.18)$ & $\mathrm{p}=0.32$ & $2.42(2.96)$ & $\mathrm{p}=0.96$ \\
\hline
\end{tabular}

Statistical comparisons are with the oesophagitis or normal group and are by oneway ANOVA. DU=duodenal ulcer. 
TABLE VII Results excluding those taking proton pump inhibitors, non-steroidal antiinflammatory drugs and those who had had previous $\mathrm{H}$ pylori eradication therapy

\begin{tabular}{lcc}
\hline$n=261$ & Sensitivity \% (95\% CI) & Specificity \% (95\% CI) \\
\hline Helisal whole blood test & $85(79-91)$ & $79 \cdot 5(72-87)$ \\
Helico-G & $94 \cdot 5(89-98)$ & $71(63-80)$ \\
Helisal serum & $95(90-98)$ & $75(67-83)$ \\
Helisal saliva & $89(83-94)$ & $64(55-73)$ \\
Slide biopsy urease & $100(97-100)$ & $100(97-100)$ \\
Histology & $95(90-98)$ & $100(97-100)$ \\
${ }^{13}$ C-urea breath test & $100(93-100)$ & $100(89-100)$
\end{tabular}

TABLE VIII Results in the under 50 age group

\begin{tabular}{lll}
\hline$n=45$ & Sensitivity (\%) & Specificity (\%) \\
\hline Helisal whole blood test & $83 \cdot 3$ & $82 \cdot 4$ \\
Helico-G & $95 \cdot 8$ & $70 \cdot 6$ \\
Helisal serum & $95 \cdot 8$ & $64 \cdot 7$ \\
Helisal saliva & $91 \cdot 7$ & $35 \cdot 3$ \\
\hline
\end{tabular}

TABLE IX Diagnoses according to age at endoscopy

\begin{tabular}{lccr}
\hline & Under 50 & Over 50 & Total \\
\hline Peptic ulcer & 2 & 20 & 22 \\
Duodenal ulcer (previous) & 3 & 9 & 12 \\
Duodenitis & 3 & 13 & 16 \\
Antral gastritis & 3 & 21 & 24 \\
Hiatus hernia & 2 & 33 & 35 \\
Normal & 26 & 106 & 132 \\
Cancer of oesophagus & - & 5 & 5 \\
Oesophagitis & 6 & 46 & 52 \\
Leiomyoma & - & 1 & 1 \\
Gastric polyp & - & 1 & 1 \\
Total & 45 & 255 & 300 \\
\hline
\end{tabular}

the unit policy). In this group the sensitivity and specificity of the serology tests did not differ significantly from those of the group as a whole. Table IX shows the under 50 and over 50 age groups broken down according to endoscopic diagnosis.

\section{COMPARISON OF ELISA ASSAYS}

The Figure shows a plot of the sensitivity and specificity of different cut off points for each of the three ELISA assays. Separate analysis of the group in whom three tests were performed for the gold standard (100 patients of whom 91 were not indeterminate) showed traces which

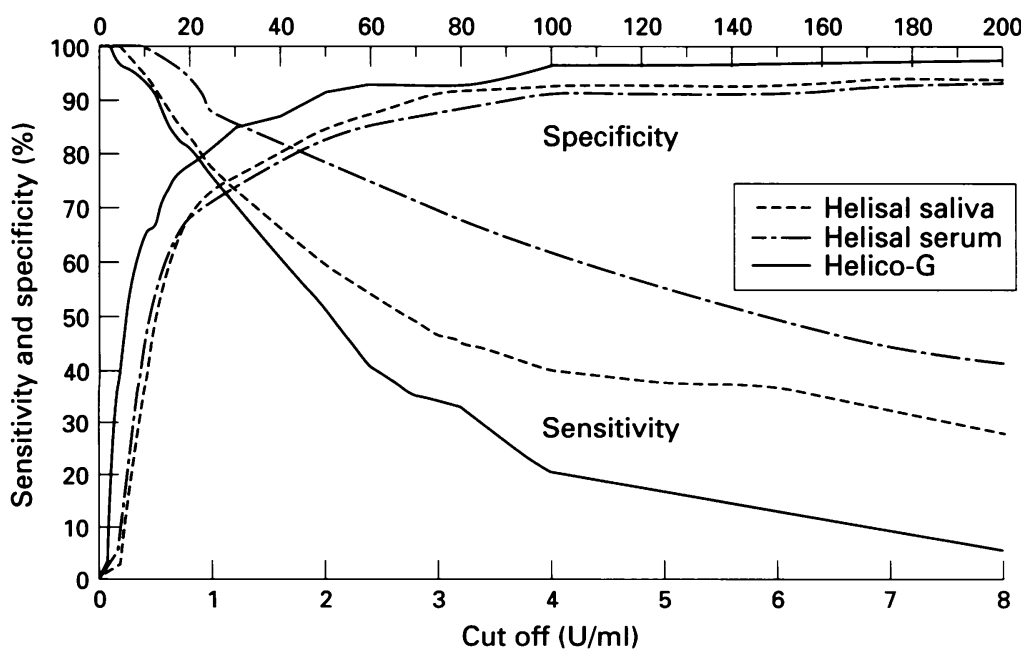

Sensitivity and specificity of three ELISA IgG assays for antibodies to $\mathrm{H}$ pylori. The top $X$ axis refers to the Helico- $G$ assay and the bottom $X$ axis to the two Helisal assays. were superimposable on those shown. Likewise exclusion of those who had been on proton pump inhibitors, non-steroidal anti-inflammatory drugs, or had had previous eradication therapy made no difference to the sensitivity of any of the assays although it did make a nonsignificant improvement to the specificity over the middle part of the cut off range.

\section{Discussion}

The sensitivity of the Helisal rapid blood test has been reported to be in the range $63 \%$ to $91 \%$ and the specificity $83 \%$ to $94 \% .^{5-8}$ In this group of subjects we found it to be $85 \%$ sensitive with a specificity of $78 \%$. The sensitivity of Helico-G ranges from $71 \%{ }^{9}$ to $96 \%{ }^{10}$ whereas reported sensitivity and specificity of the Cortecs serum ELISA test are $91.2 \%$ and $83.3 \%$ respectively. ${ }^{11}$ The sensitivity and specificity levels we found are in line with those previously published for both of these assays. Salivary IgG antibodies to Helicobacter have been reported to have a sensitivity of $89 \%-90 \%$ and a specificity of $82 \%-94 \%,{ }^{12} 13$ and the particular assay we used has previously been validated against a serum assay, ${ }^{14}$ and when tested clinically ${ }^{15}$ it provided a sensitivity of $97 \%$ and a specificity of $90 \%$. In our hands the salivary assessment achieved somewhat lower sensitivity and specificity than those previously reported. However, our study included a much larger group of subjects than most previous reports and is in line with other results. From our data we conclude that the new rapid whole blood test has a lower sensitivity than desirable if it were to be used to determine appropriate dyspeptic patients for endoscopy. Such a test requires high sensitivity so that few if any diagnoses associated with $H$ pylori are missed.

The study may be criticised and the conclusion questioned for various reasons. The average age of our subjects (62) was higher than that of most series: this is because our endoscopy unit operates a screening policy which has the effect of excluding the young and fit from endoscopy. This could reduce the sensitivity of serology based tests because the serological response to $H$ pylori infection declines with age. However, the subgroup analysis on those under 50 showed similar serology results to those of the whole study population, and this suggests that in our population age alone cannot account for low sensitivity of the rapid assay. Similarly, age alone would not explain the difference between serum ELISA studies and the rapid blood test.

We did not take biopsy specimens from the gastric body: this omission may have lowered the number of positives diagnosed by the gold standard if there were cases in whom $H$ pylori was present in the gastric body but not in the antrum as is reported to occur after treatment with proton pump inhibitors. ${ }^{16}$ It can be argued that the extra biopsy specimens might have resolved some of the indeterminates. However, in only 11 out of the 26 indeterminates was the histology negative. If all of these had had positive corpus biopsy specimens the sensitivity 
of the rapid whole blood test would have been $84 \%$ (compared with $85 \%$ ), of Helico-G $92.5 \%$ (94\%), of Helisal serum $94.6 \%$ (95\%), and of Helisal saliva $89 \%(84 \%)$. If it were assumed that the indeterminates were lowlevel positives, analysis of results (middle column of Table I) shows that their inclusion reduces the sensitivity of all the tests with the exception of the slide biopsy urease test. One hundred breath tests only were performed because of practicality and expense, but separate analysis of the patients who received them showed similar results to those of the group as a whole, suggesting that the gold standard criteria we chose were adequate.

We made no exclusions other than those due to the screening policy in operation, because we thought that the study conditions should reflect as closely as possible the conditions under which the blood tests are likely to be used. We therefore included some patients who had previously had eradication therapy, or who had been taking proton pump inhibitors, which can suppress Helicobacter without eradicating $\mathrm{it}^{17}$ and who had been on aspirin and nonsteroidal anti-inflammatory drugs. Both of the first two factors could have led serological tests to overdiagnose infection by comparison with the gold standard, and hence have affected the specificity but not the sensitivity. A subanalysis of the group excluding the 41 patients who had been on, proton pump inhibitors, or had had eradication therapy made no difference to the sensitivity of any of the candidate tests while slightly but not significantly improving the specificity. The inclusion of those on nonsteroidal anti-inflammatory drugs led to the inclusion of one patient with a duodenal ulcer who was $H$ pylori negative by the gold standard.

The performance of the rapid test in predicting Helicobacter related pathology was not quite as good as that of the two serum ELISA tests: our results suggest that the whole blood test, if used as a screening bar to endoscopy, would result in about $15 \%$ of those with the infection and $10 \%$ of those with current ulcers going undetected. The results for the saliva assay are similar. Our study population was a relatively highly selected one of dyspeptic patients deemed by their general practitioners to require endoscopy. Therefore they would be expected to have a high prevalence of $H$ pylori. As negative predictive value (the chance of a negative result correctly placing its subject) increases with lower prevalence of an organism the confidence with which a subject could be declared free of infection on the basis of a negative rapid test may be higher in less selected populations than ours.

We would not recommend the routine use of salivary antibodies as a means to choose appropriate endoscopy in $H$ pylori positive patients in whom the test is considered. The rapid whole blood test has the advantages that it is portable, no special equipment (such as centrifuges) is required to perform it, and it gives a result within five to seven minutes. In settings where ELISA assays are not available a positive result with this kit would be helpful in decision making, but the result would ideally be confirmed by other means. The serum ELISA assays tested provide higher sensitivity levels and where available remain our choice.

We thank Professor J Temple, Mr M Hallissey, Mr M Corlett, Dr N Michell, Dr Kate Kane, and the staff of QED and the Clinical Investigation Unit of the Queen Elizabeth Hospital for their help with this study, which was supported by a grant from Cortecs Ltd.

1 Sobala GM, Crabtree JE, Pentith JA, Rathbone BJ, Shallcross TM, Wyatt JI, et al. Screening dyspepsia by

2 Mendall MA, Jazrawi RP, Marrero JM, Molineaux N, Levi J, Maxwell JD, Northfield TC. Serology for Helicobacter pylori compared with symptom questionnaires in screening before direct access endoscopy. Gut 1995; 36: screening

3 European standard protocol. Eur $\mathcal{f}$ Gastroenterol Hepatol 1991; 3: 915-21.

4 Price AB. The Sydney system: histological division. $f$ Gastroenterol Hepatol 1991; 6: 209-22.

5 Duggan AE, Knifton A, Logan RPH, Hawkey CI, Logan RFA. Validation of two new rapid blood tests for Helicobacter pylori. Gut 1995; 37(suppl 2): A85.

6 Lahaie RG, Ricard N. Validation of Helisal whole blood, serum and saliva tests for the non-invasive diagnosis of Helicobacter pylori infection. Gut 1995; 37(suppl 1): A13.

7 Millar Jones D, Yapp T, Thomas GAO, Pugh S. A new rapid whole blood test for Helicobacter pylori antibodies could reduce diagnostic oesophagogastroduodenoscopy (OGD) in patients with dyspepsia. Gut 1994; 35(suppl 5): S1.

8 Moayeddi P, Carter AM, Heppell RM, Catto AJ, Grant P, Axon ATR. Validation of a new rapid whole blood test for the diagnosis of Helicobacter pylori infection. Gut 1995; 36(suppl 1): A51

9 Jensen AK, Andersen LP, Wachmann $\mathrm{CH}$. Evaluation of eight commercial kits for Helicobacter pylori IgG antibody detection. APMIS 1993; 101: 795-801.

10 Uyub AM, Anuar AK, Aiyar S. Reliability of two commercial serological kits for serodiagnosing Helicobacter pylori infection. Southeast Asian $\mathcal{F}$ Trop Med Public Health 1994; 25: 316-20.

11 Pugh S, Swift J, Landeg S. Helicobacter pylori IgG antibody status in hospital staff groups: results using the cortecs ELISA test. In: Abstracts submitted for Helicobacter pylori: beginning the second decade-the VIIth workshop of the European Helicobacter pylori Study Group, 1994. Am F Gastroenterol 1994; 89: 1285-422.

12 Patel P, Mendall MA, Khulusi S, Molineaux N, Levy J, Maxwell JD, Northfield TC. Salivary antibodies to Helicobacter pylori: screening dyspeptic patients before endoscopy. Lancet 1994; 344: 511-2.

13 Clancy RI, Cripps AW, Taylor DC, McShane L, Webster VJ. The clinical value of a saliva diagnostic assay for antibody to $\mathrm{H}$ pylori. In: Hunt RH, Tytgat GNJ, eds. for antibody to $\mathrm{H}$ pylori. In: Hunt RH, Tytgat GNJ, eds. Helicobacter pylori - basic mechanisms to clinical cure.
Proceedings of the International Symposium held in Amelia Island, Florida USA, 3-6 November 1993. Dordrecht: Kluwer Academic, 1994.

4 Phull P, Goodwin P, Guard P, et al. Detection of saliva antibody to $\mathrm{H}$ pylori by the Helisal ${ }^{\mathrm{TM}}$ enzyme-linked immunosorbent assay. In: Hunt RH, Tytgat GNJ, eds. Helicobacter pylori- basic mechanisms to clinical eds. Proceedings of the Isicher Amelia Island, Florida USA, 3-6 November 1993. Dordrecht: Kluwer Academic, 1994.

15 Lahaie RG, Ricard N. Validation of helisal whole blood, serum and saliva tests for the non-invasive diagnosis of Helicobacter pylori infection. Gut 1995; 37(suppl 1):
Helumesis of A13.

16 Logan RP, Walker MM, Misiewicz J, Gummett PA, Karim QN, Baron JH. Changes in the intragastric distribution of Helicobacter pylori during treatment with omeprazole. Gut 1995; 36: 12-6.

17 Weil J, Bell GD, Powell K, et al. Omeprazole and Helicobacter pylori: temporary suppression rather than true eradication. Aliment Pharmacol Ther 1991; 5: 309-13. 